\title{
Pharmacokinetics of cannabichromene in a medical cannabis product also containing cannabidiol and $\Delta^{9}$-tetrahydrocannabinol: a pilot study
}

\author{
Erica N. Peters ${ }^{1} \cdot$ Laura MacNair $^{1} \cdot$ Irina Mosesova $^{1} \cdot$ Uwe Christians $^{2} \cdot$ Cristina Sempio $^{2} \cdot$ Jost Klawitter $^{2}$. \\ M. Hunter Land ${ }^{1} \cdot$ Mark A. Ware $^{1} \cdot$ Cynthia Turcotte $^{1} \cdot$ Marcel O. Bonn-Miller $^{1}$
}

Received: 28 April 2021 / Accepted: 11 October 2021 / Published online: 18 October 2021

(c) The Author(s) 2021

\begin{abstract}
Purpose Cannabichromene (CBC) is a phytocannabinoid commonly found in cannabis, yet its acute post-dose pharmacokinetics (PK) have not been examined in humans. This is a secondary data analysis from a trial investigating Spectrum Yellow oil, an oral cannabis product used for medical purposes that contained $20 \mathrm{mg}$ cannabidiol (CBD), $0.9 \mathrm{mg} \Delta^{9}$ tetrahydrocannabinol (THC), and $1.1 \mathrm{mg} \mathrm{CBC}$, per $1 \mathrm{~mL}$ of oil.

Methods Participants $(N=43)$ were randomized to one of 5 groups: $120 \mathrm{mg} \mathrm{CBD}, 5.4 \mathrm{mg}$ THC, and $6.6 \mathrm{mg}$ CBC daily; $240 \mathrm{mg}$ CBD, $10.8 \mathrm{mg}$ THC, and $13.2 \mathrm{mg} \mathrm{CBC}$ daily; $360 \mathrm{mg} \mathrm{CBD}, 16.2 \mathrm{mg}$ THC, and $19.8 \mathrm{mg}$ CBC daily; $480 \mathrm{mg}$ CBD, $21.6 \mathrm{mg}$ THC, and $26.4 \mathrm{mg}$ CBC daily; or placebo. Study medication was administered every $12 \mathrm{~h}$ for 7 days. Plasma CBC concentrations were analyzed by a validated two-dimensional high-performance liquid chromatography-tandem mass spectrometry assay.

Results After a single dose and after the final dose, the $C_{\max }$ of CBC increased by 1.3-1.8-fold for each twofold increase in dose; the $t_{\max }$ range was 1.6-4.3 $\mathrm{h}$. Based on the ratio of administered CBD, THC, and CBC to the plasma concentration, the dose of CBD was 18 times higher than the dose of $\mathrm{CBC}$, yet the $\mathrm{AUC}_{0-t}$ of $\mathrm{CBD}$ was only 6.6-9.8-fold higher than the $\mathrm{AUC}_{0-t}$ of $\mathrm{CBC}$; the dose of THC was similar to the dose of CBC, yet THC was quantifiable in fewer plasma samples than was CBC. Conclusions CBC may have preferential absorption over CBD and THC when administered together.

Trial Registration: Australian New Zealand Clinical Trials Registry \#ACTRN12619001450101, registered 18 October 2019.
\end{abstract}

Keywords Cannabichromene $\cdot$ Phytocannabinoid $\cdot$ Pharmacokinetics $\cdot$ Cannabis

\section{Introduction}

Medical use of cannabis to treat a variety of therapeutic indications is growing worldwide [1]. Most medical cannabis products report the concentration of two of the most abundant and widely studied phytocannabinoids, $\Delta^{9}$ tetrahydrocannabinol (THC) and cannabidiol (CBD). However, cannabis contains over 120 phytocannabinoids, most

Erica N. Peters

erica.peters@canopygrowth.com

1 Canopy Growth Corporation, One Hershey Drive, Smiths Falls, ON, Canada

2 iC42 Clinical Research and Development, Department of Anesthesiology, University of Colorado Anschutz Medical Campus, Aurora, CO, USA having unique pharmacological properties. One "minor" phytocannabinoid, cannabichromene (CBC), is commonly found in cannabis and ranges in published studies from 0.05 and $0.3 \% \mathrm{w} / \mathrm{w}[2-6]$.

In vitro pharmacological assays have revealed that $\mathrm{CBC}$ has multiple targets, including direct and indirect effects on the endocannabinoid system (ECS). CBC has low binding affinity and no appreciable activity at cannabinoid type 1 receptors (CB1), the receptor responsible for the intoxicating effects of THC [7]. However, CBC is a more efficacious cannabinoid type 2 receptor (CB2) agonist than THC, suggesting that $\mathrm{CBC}$ may be an effective anti-inflammatory agent [8]. CBC can inhibit endocannabinoid cellular reuptake and is a weak inhibitor of monacylglycerol lipase (MAGL), which may affect endocannabinoid tone $[9,10]$. In addition to its action on the ECS, CBC is a potent activator and desensitizer of transient receptor potential (TRP) ankyrin 
1-type (TRPA1) channels, indicating that $\mathrm{CBC}$ could be an antinociceptive agent $[10,11]$.

Preclinical research has identified several avenues of therapeutic potential that generally corroborate with in vitro pharmacological data. In vitro functional data show that CBC increases viability of adult neural progenitor cells and inhibited their differentiation into astroglia, suggesting that $\mathrm{CBC}$ may be a candidate for treating neuroinflammatory diseases [12]. In rodents, CBC has displayed anti-microbial, anti-inflammatory, analgesic, and anti-depressant-like activity [13-21].

Despite evidence from preclinical studies suggesting the therapeutic potential of $\mathrm{CBC}$, its effects in humans have largely not been examined. One study detected CBC in plasma samples from medical cannabis patients who consumed CBD oil [22]. Another study assessing the efficacy and tolerability of a 1:20 THC:CBD medical cannabis product in children with treatment-resistant epileptic encephalopathy reported that the product contained $4 \% \mathrm{CBC}$ by volume and described steady state trough levels of CBC [23]. However, acute post-dose pharmacokinetic (PK) data on CBC are critical to inform dosing schedules in future studies that evaluate the potential therapeutic effects of CBC in humans, and to understand how co-administration of multiple phytocannabinoids may impact the PK of each. The present pilot study examined the PK of CBC in human plasma from a study of a standardized oral medical cannabis product that contained $20 \mathrm{mg} / \mathrm{mL} \mathrm{CBD}, 0.9 \mathrm{mg} / \mathrm{mL}$ THC, and $1.1 \mathrm{mg} /$ $\mathrm{mL} \mathrm{CBC.}$

\section{Methods and materials}

The parent study was a Phase 1, randomized, double-blind, placebo-controlled, multiple-dose trial in 43 healthy participants to assess the safety, tolerability, PK, and PD of Spectrum Yellow oil [24]. The study was conducted in accordance with consensus ethics principles, International Conference on Harmonization Good Clinical Practice guidelines, the Declaration of Helsinki, and local Australian laws and regulations. The protocol was approved by the Alfred Hospital Ethics Committee (Melbourne, Victoria, Australia). Written informed consent was obtained from each participant before any trial-related procedures were performed.

Spectrum Yellow oil (Tweed Inc., Canopy Growth Corporation, Smiths Falls, ON, Canada) is a cannabis-based product that is currently commercially available in Canada, Australia, United Kingdom, and Cayman Islands. Spectrum Yellow oil was made with supercritical carbon dioxide extracted cannabis resin in medium-chain triglyceride (MCT) oil. Analytical testing of the clinical batch detected $20 \mathrm{mg} / \mathrm{mL}$ CBD and $0.9 \mathrm{mg} / \mathrm{mL}$ THC, plus a total terpene concentration $<0.05 \%$. Analytical testing of the clinical batch also detected the presence of $\mathrm{CBC}$ at a relatively high concentration $(1.1 \mathrm{mg} / \mathrm{mL})$, thus prompting the present subanalysis of the CBC time-concentration data. Analytical testing revealed that other cannabinoids were either below the reporting limit $(<0.50 \mathrm{ng} / \mathrm{mL})$ or not detected.

Participants were randomly assigned to one of five groups in a 1:1:1:1:1 ratio: $120 \mathrm{mg}$ CBD, $5.4 \mathrm{mg}$ THC, and $6.6 \mathrm{mg}$ CBC daily (Treatment A); $240 \mathrm{mg} \mathrm{CBD}, 10.8 \mathrm{mg}$ THC, and $13.2 \mathrm{mg}$ CBC daily (Treatment B); $360 \mathrm{mg}$ CBD, $16.2 \mathrm{mg}$ THC, and $19.8 \mathrm{mg} \mathrm{CBC}$ daily (Treatment C); $480 \mathrm{mg} \mathrm{CBD}$, $21.6 \mathrm{mg}$ THC, and $26.4 \mathrm{mg}$ CBC daily (Treatment D); or placebo. Participants were confined to a residential research facility and received study medication twice daily, approximately every $12 \mathrm{~h}$, after a standardized meal (e.g., for breakfast, 2 cups of cereal; 2 slices of toast; 2 servings of butter or margarine; 2 condiments; $250 \mathrm{~mL}$ of milk; 1 sugar sachet) for 6 days, plus a single dose in the morning of day 7. PK blood samples included in this analysis were collected prior to the morning dose and $1,2,4,6,8$, and $12 \mathrm{~h}$ after the morning dose on day 1 ; prior to the morning dose and $1,2,4,6,8,12$, and $16 \mathrm{~h}$ after the morning dose on day 7 ; and 24, 32, 48, 72, 96, and $144 \mathrm{~h}$ after the day 7 morning dose. Immediately following collection, blood samples were placed on wet ice and centrifuged, and plasma was immediately frozen at $-80^{\circ} \mathrm{C}$ until shipment to the bioanalytical laboratory (iC42 Clinical Research and Development, University of Colorado, Aurora, CO, USA) on dry ice. Samples were stored at the bioanalytical laboratory at $-80^{\circ} \mathrm{C}$.

CBC plasma concentrations were analyzed using a twodimensional high-performance liquid chromatography-tandem mass spectrometry assay developed and validated by iC42 Clinical Research and Development [22], and study samples were analyzed in a CLIA (United States Clinical Laboratory Improvement Amendments)-certified laboratory environment accredited by the College of American Pathologists (Northfield, IL, USA). For details of the analytic method, please see Klawitter et al. [22]. The lower limit of quantification (LLoQ) of $\mathrm{CBC}$ was $0.78 \mathrm{ng} / \mathrm{mL}$ [22]; samples with concentrations below the LLoQ were treated as 0 in the analysis. Urinary excretion of CBC was not examined in this pilot study. PK parameters were calculated using non-compartmental analysis (Phoenix WinNonlin version 8.2., Certara, Princeton, NJ, USA). Statistical analysis was carried out using SPSS (version 27.0, IBM, Armonk, NY, USA).

\section{Results}

Results on participant characteristics, safety and tolerability of Spectrum Yellow oil, and PK of CBD and THC in Spectrum Yellow oil are presented in the parent publication [24]. The overall conclusion was that Spectrum Yellow oil was safe and well-tolerated. 


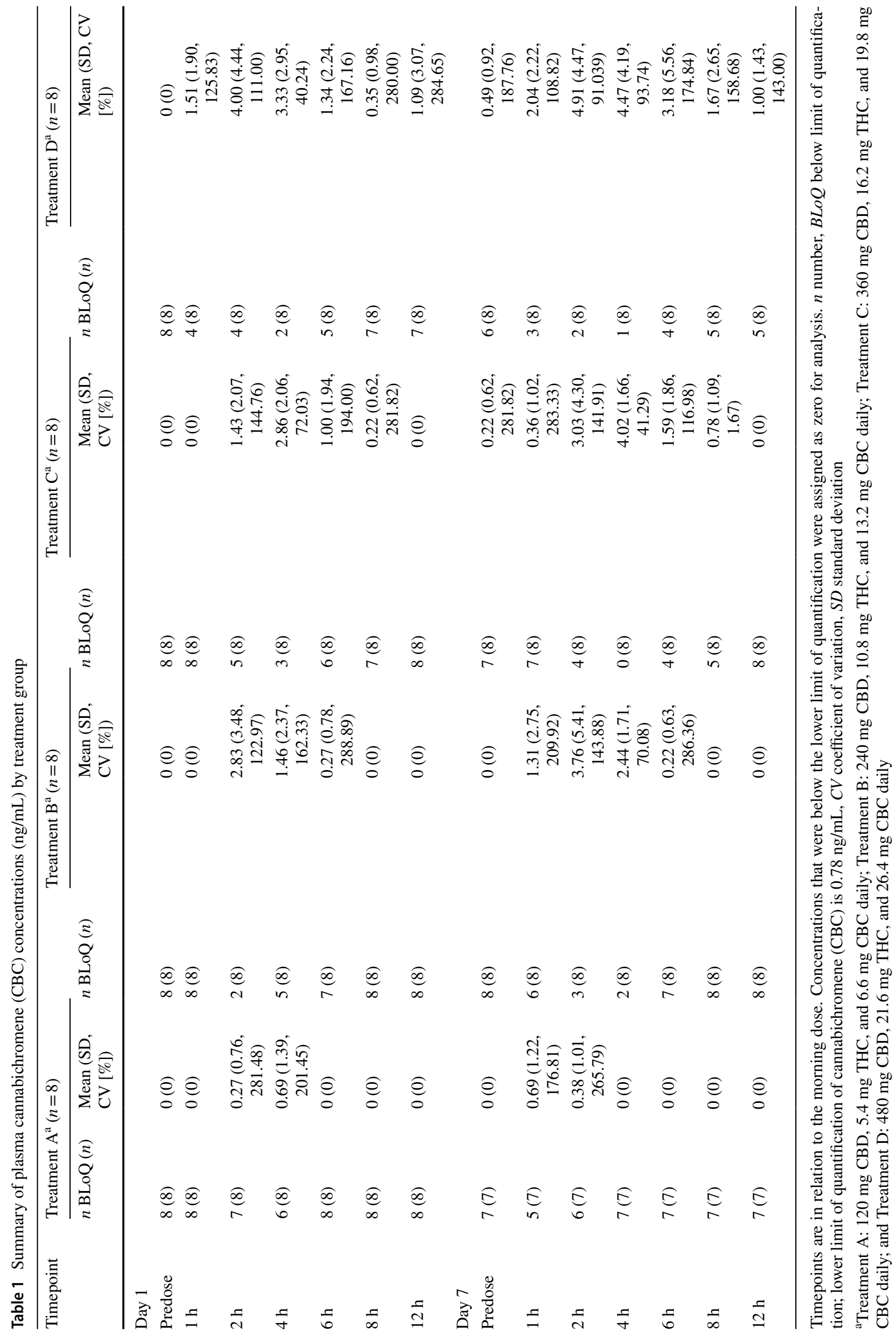


The majority of plasma samples on both days 1 and 7 had quantifiable concentrations of CBC except for Treatment A, where most samples were below the LLoQ (Table 1). Within each treatment group, there was notable variability between participants with respect to mean concentrations of CBC at each timepoint (Table 1). At an individual level, there appeared to be three different plasma concentration-time profiles of measured cannabinoids. Supplementary Material displays these three different profiles for participants in Treatment $\mathrm{D}$ on day 7: there was either low absorption of CBD and no absorption of either THC or CBC (Supplementary Material A), moderate absorption of CBD and CBC and no absorption of THC (Supplementary Material B), or high absorption of CBD, THC, and CBC (Supplementary Material C).

Table 2 presents the summary plasma PK parameters for CBC. After a single dose on day 1, the maximum observed plasma concentration $\left(C_{\max }\right)$ for $\mathrm{CBC}$ increased by 1.3 - and 1.8-fold with each twofold increase in dose between Treatments $\mathrm{A}$ and $\mathrm{B}$, and Treatments $\mathrm{B}$ and $\mathrm{D}$; the median time to peak plasma concentration $\left(t_{\max }\right)$ ranged $2.3-4.3 \mathrm{~h}$ across treatments. On days 2-7, almost all pre-dose concentrations of CBC were below the LLoQ in Treatments A, B, and C. On days $2-7,3$ of 8 participants in Treatment $D$ had some quantifiable concentrations of $\mathrm{CBC}$, but these were sporadic. Thus, steady-state concentration of CBC could not be calculated.

Moderate accumulation was noted on day 7 after a week of twice-daily dosing of Spectrum Yellow oil, with the $C_{\max }$ increasing by 1.4- and 1.7-fold, and the area under the curve from time 0 to $12 \mathrm{~h}\left(\mathrm{AUC}_{0-12}\right)$ increasing by 1.6- and 3.3-fold with each twofold increase in dose of CBC between Treatments A and B, and Treatments B and D. On day 7, the median $t_{\max }$ of CBC ranged $1.6-4.3 \mathrm{~h}$ across treatments. The $\mathrm{CL} / \mathrm{F}$ of $\mathrm{CBC}$ was only calculable for Treatments $\mathrm{C}$ and $\mathrm{D}$, and ranged $0.12-0.22 \mathrm{~L} / \mathrm{h}$. On Days 1 and 7, while the dose of CBD was 18 times higher than that of $\mathrm{CBC}$, the area under the curve from time 0 to last measurable concentration $\left(\mathrm{AUC}_{0-t}\right.$ ) of $\mathrm{CBD}$ was only 6.6-9.8 fold higher than that of CBC (in Treatment D, where $\mathrm{CBC}$ was quantifiable in most samples); the dose of THC was similar to the dose of CBC, yet THC was quantifiable in fewer plasma samples than CBC.

Table 2 Plasma pharmacokinetic parameters for cannabichromene (CBC)

\begin{tabular}{|c|c|c|c|c|c|c|c|c|}
\hline \multirow{2}{*}{$\begin{array}{l}\text { Pharmacokinetic } \\
\text { parameter (unit) }\end{array}$} & \multicolumn{2}{|c|}{ Treatment $\mathrm{A}^{\mathrm{a}}(n=8)$} & \multicolumn{2}{|c|}{ Treatment $\mathrm{B}^{\mathrm{a}}(n=8)$} & \multicolumn{2}{|c|}{ Treatment $\mathrm{C}^{\mathrm{a}}(n=8)$} & \multicolumn{2}{|c|}{ Treatment $\mathrm{D}^{\mathrm{a}}(n=8)$} \\
\hline & Day 1 & Day 7 & Day 1 & Day 7 & Day 1 & Day 7 & Day 1 & Day 7 \\
\hline$C_{\max }(\mathrm{ng} / \mathrm{mL})^{\mathrm{b}}$ & $2.4(43.6)^{\mathrm{d}}$ & $2.8(6.6)^{\mathrm{e}}$ & $3.6(60.1)^{\mathrm{f}}$ & $4.0(56.3)^{\mathrm{g}}$ & $4.8(20.9)^{\mathrm{f}}$ & $4.2(43.1)$ & $6.6(31.9)^{\mathrm{h}}$ & $6.7(42.6)^{\mathrm{g}}$ \\
\hline$t_{\max }(\mathrm{h})^{\mathrm{c}}$ & $3.2(0.0-4.3)^{\mathrm{d}}$ & $1.6(1.3-2.0)^{\mathrm{e}}$ & $2.3(2.0-4.5)^{\mathrm{f}}$ & $2.3(2.0-4.3)^{\mathrm{g}}$ & $4.3(4.2-4.4)^{\mathrm{f}}$ & $4.3(2.3-4.3)$ & $3.4(2-12.3)^{\mathrm{h}}$ & $2.3(2.3-8.3)^{\mathrm{g}}$ \\
\hline$\underset{\mathrm{mL}^{-\mathrm{b}}}{\mathrm{AUC}_{0^{\mathrm{b}}}}\left(\mathrm{ng}{ }^{*} \mathrm{~h} /\right.$ & $2.2(75.2)^{\mathrm{i}}$ & $2.3(35.0)^{\mathrm{e}}$ & $5.6(83.9)^{f}$ & $5.9(74.1)^{\mathrm{g}}$ & $9.0(41.4)^{\mathrm{f}}$ & $9.9(47.3)$ & $17.6(37.4)^{\mathrm{h}}$ & $26.8(31.6)^{\mathrm{g}}$ \\
\hline $\begin{array}{l}\mathrm{AUC}_{0-12}(\mathrm{~h} * \mathrm{ng} / \\
\mathrm{mL})^{\mathrm{b}}\end{array}$ & - & $5.7(3.4)^{\mathrm{e}}$ & - & $9.0(46.3)^{\mathrm{g}}$ & - & $13.6(34.5)$ & - & $29.5(26.5)^{\mathrm{g}}$ \\
\hline $\begin{array}{l}\mathrm{AUC}_{0-\text { inf }}(\mathrm{h} * \mathrm{ng} / \\
\mathrm{mL})^{\mathrm{b}}\end{array}$ & $\mathrm{NE}$ & $\mathrm{NE}$ & $\mathrm{NE}$ & NE & $\mathrm{NE}$ & $44.2(6.9)^{\mathrm{e}}$ & $\mathrm{NE}$ & $107.8(-)^{\mathrm{j}}$ \\
\hline $\begin{array}{l}\% \text { extrapolated } \\
\left(\mathrm{AUC}_{12-\infty} / \mathrm{AUC}\right. \\
0-\infty)^{\mathrm{b}}\end{array}$ & NE & $\mathrm{NE}$ & $\mathrm{NE}$ & NE & $\mathrm{NE}$ & $\begin{array}{l}18.22 \% \\
(5.91 \%)^{\mathrm{e}}\end{array}$ & $\mathrm{NE}$ & $26.6 \%(-)^{j}$ \\
\hline $\mathrm{CL} / \mathrm{F}(\mathrm{L} / \mathrm{h})^{\mathrm{b}}$ & - & $\mathrm{NE}$ & - & NE & - & $0.22(17.4)^{\mathrm{e}}$ & - & $0.12(-)^{j}$ \\
\hline
\end{tabular}

Concentrations that were below the lower limit of quantification were assigned as zero for analysis. $A U C_{0-12}$ area under the plasma concentration-time curve from 0 - to 12-h time point, $A U C_{0-t}$ area under the plasma concentration-time curve from 0 to the last quantifiable concentration, $A U C_{0-\text { inf }}$ area under the plasma concentration-time curve from 0 to infinity, $C L / F$ oral clearance of drug from plasma, $C_{\max }$ maximum observed plasma concentration, $N E$ not estimable, $t_{\max }$ time to reach $C_{\max }$

${ }^{a}$ Treatment A: $120 \mathrm{mg} \mathrm{CBD}, 5.4 \mathrm{mg}$ THC, and $6.6 \mathrm{mg} \mathrm{CBC}$ daily; Treatment B: $240 \mathrm{mg}$ CBD, $10.8 \mathrm{mg}$ THC, and $13.2 \mathrm{mg}$ CBC daily; Treatment C: $360 \mathrm{mg} \mathrm{CBD}, 16.2 \mathrm{mg}$ THC, and $19.8 \mathrm{mg} \mathrm{CBC}$ daily; and Treatment D: $480 \mathrm{mg}$ CBD, $21.6 \mathrm{mg}$ THC, and $26.4 \mathrm{mg}$ CBC daily

${ }^{\mathrm{b}}$ Geometric mean (geometric CV\%)

${ }^{\mathrm{c}}$ Median (range)

${ }^{\mathrm{d}} n=4$

${ }^{\mathrm{e}} n=2$

${ }^{\mathrm{f}} n=5$

$\mathrm{g}_{n=7}$

${ }^{\mathrm{h}} n=6$

${ }^{\mathrm{i}} n=3$

$\mathrm{j}_{n=1}$ 
Fig. 1 Geometric mean ( \pm standard deviation) plasma concentration-time profiles for cannabichromene (CBC) in Spectrum Yellow oil on day 1 and day 7 for Treatment A: $120 \mathrm{mg} \mathrm{CBD}, 5.4 \mathrm{mg}$ THC, and $6.6 \mathrm{mg}$ CBC daily; Treatment B: $240 \mathrm{mg} \mathrm{CBD}, 10.8 \mathrm{mg}$ THC, and $13.2 \mathrm{mg}$ CBC daily; Treatment C: $360 \mathrm{mg} \mathrm{CBD}, 16.2 \mathrm{mg}$ THC, and $19.8 \mathrm{mg} \mathrm{CBC}$ daily; and Treatment D: $480 \mathrm{mg} \mathrm{CBD}$, $21.6 \mathrm{mg}$ THC, and $26.4 \mathrm{mg}$ CBC daily. Concentrations that were below the lower limit of quantification $(0.78 \mathrm{ng} /$ $\mathrm{mL}$ ) were assigned as zero for analysis

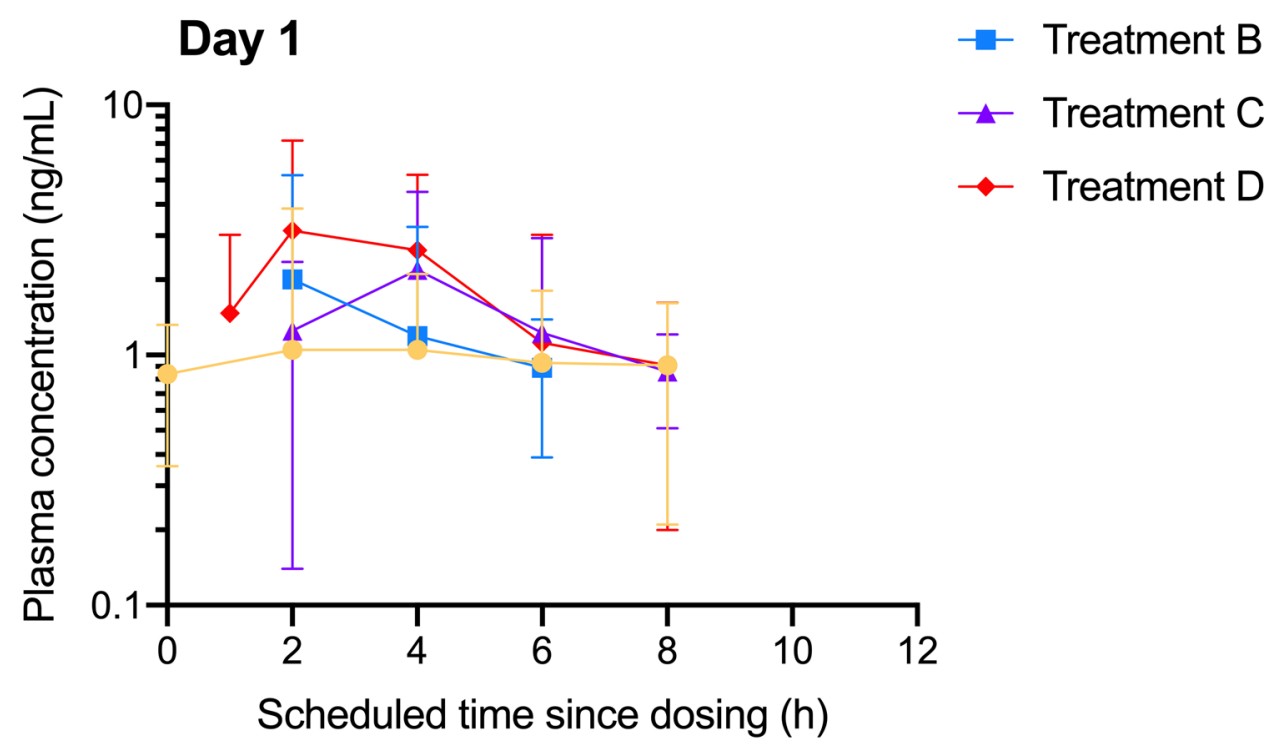

\section{Day 7}

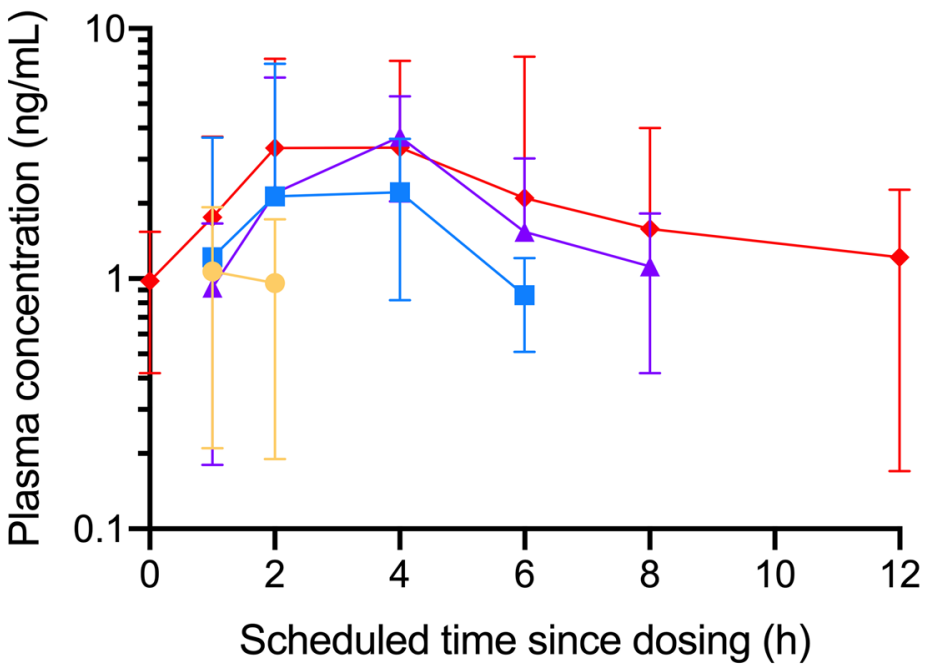

Figure 1 shows the plasma concentration-time curves for $\mathrm{CBC}$ on days 1 and 7. These data suggested a dosedependent increase in $\mathrm{CBC}$ plasma concentrations, although considerable variability was observed.

\section{Discussion}

After a single dose, as well as a week of twice-daily dosing, of an oral cannabis product containing CBD, THC, and $1.1 \mathrm{mg} / \mathrm{mL} \mathrm{CBC}$, the $C_{\max }$ of CBC increased by $1.3-1.7$-fold for each twofold increase in dose. Further, the observed CBC $t_{\max }$ ranged between 1.6 and $4.3 \mathrm{~h}$, with between-participant variability in plasma concentrations of $\mathrm{CBC}$.
A major finding of the parent study was that Spectrum Yellow oil was well-tolerated in healthy participants at daily doses up to $480 \mathrm{mg}$ CBD and $20 \mathrm{mg}$ THC [24]. Because Spectrum Yellow oil also contained $1.1 \mathrm{mg} / \mathrm{mL} \mathrm{CBC}$, it can thus be inferred that, in the presence of CBD and THC, $\mathrm{CBC}$ is well-tolerated up to daily doses of $26.4 \mathrm{mg}$. However, the present investigation was prompted by the observation that $\mathrm{CBC}$ was present in the clinical batch, and the studied doses (6.6-26.4 mg CBC daily) were not a priori based on doses found to be effective in published preclinical studies [13-21]. Future research evaluating the therapeutic potential of CBC may wish to study higher doses, and may need to collect data on safety at such doses. 
Plasma concentrations of $\mathrm{CBC}$ were generally higher and more consistently quantifiable than those of CBD and THC at the same lower limit of quantification [24], relative to the dose administered. More specifically, while the dose of CBD was 18 times higher than the dose of CBC, the $\mathrm{AUC}_{0-t}$ of $\mathrm{CBD}$ was only 6.6-9.8 fold higher than the $\mathrm{AUC}_{0-t}$ of $\mathrm{CBC}$ (in Treatment $\mathrm{D}$, where $\mathrm{CBC}$ was quantifiable in most samples); while the dose of THC was similar to the dose of $\mathrm{CBC}$, THC was quantifiable in fewer plasma samples than CBC [24]. These data suggest that CBC may have preferential absorption over CBD or THC when administered together in Spectrum Yellow oil. It is interesting to note that clinical studies reported in the literature have produced conflicting findings on the interaction of different phytocannabinoids on each other's pharmacokinetics. For example, in one study CBD delayed the time to reach peak plasma concentrations of THC [25], while other studies have shown that combining CBD with THC may lead to an increased peak concentration of plasma THC [26, 27], and others have shown no significant effect of CBD on the pharmacokinetics of THC [28]. These conflicting findings may partially be attributed to differences in cannabinoids and other compounds contained in the tested formulations.

As the presence of CBC appears common at low levels in CBD oils [22], it is important for future studies to compare the individual PK of CBD as well as CBC when administered as isolates to humans, to that of a product containing both $\mathrm{CBD}$ and $\mathrm{CBC}$. Future studies should also investigate the effects of $\mathrm{CBC}$ on drug metabolism pathways, and should elucidate potential mechanisms underlying any interaction of multiple phytocannabinoids on pharmacokinetics, including rate and extent of absorption, competition for plasma protein binding, and inhibition/ induction of cytochrome P450s that impact metabolism as well as of active drug transporters. Because this was a pilot study, a full pharmacokinetic study of $\mathrm{CBC}$, including urinary excretion of $\mathrm{CBC}$, is warranted.

\section{Conclusions}

To our knowledge, these are the first data on the acute post-dose pharmacokinetics of the phytocannabinoid cannabichromene (CBC) in humans. At daily doses up to $26.4 \mathrm{mg}, \mathrm{CBC}$ in the presence of CBD and THC appears to be well-tolerated and is quantifiable in plasma in humans. Based on the ratio of administered phytocannabinoids to the amount measured in plasma, CBC may have preferential absorption over CBD and THC when administered together. CBC appears to be a viable target for further pharmacokinetic and therapeutic investigation.
Supplementary information The online version contains supplementary material available at https://doi.org/10.1007/s00228-021-03232-8.

Acknowledgements We acknowledge Clinical Network Services and Nucleus Network for collecting study data; Roland Jbeily, Justin Verwoert, and Ryan Yablonsky for facilitating shipment of study products; Ryan Schilling at iC42 Clinical Research and Development for analyzing plasma samples; and Aleksandra Trajkovic for assisting with study operations.

Author contribution Drs. Peters and Bonn-Miller and Mr. Land conceived of the study. Drs. MacNair, Christians, Sempio, and Klawitter and Ms. Mosesova performed the research and analyzed the data. Dr. Peters, Mr. Land, and Dr. Ware interpreted the data. Drs. Peters, MacNair, Christians, Sempio, and Klawitter and Ms. Mosesova and Ms. Turcotte drafted the manuscript. All authors provided critical revisions to the manuscript and approved of the final version.

Funding This research was supported by Canopy Growth Corporation.

Availability of data and material The dataset analyzed during the current study is available from the corresponding author on reasonable request.

Code availability Not applicable.

\section{Declarations}

Ethics approval This trial was approved by the Alfred Hospital Ethics Committee (Project No. 591/19; approved 25 November 2019).

Consent to participate Written informed consent was obtained from each participant before any trial-related procedures were performed.

Consent for publication Written informed consent to have de-identified data submitted for publication was obtained from each participant before any trial-related procedures were performed.

Conflict of interest Dr. Peters is an employee of Canopy Growth Corporation, during which time she has received stock options. She also serves as a consultant to Battelle. Dr. MacNair is an employee of Canopy Growth Corporation, during which time she has received stock options. Ms. Mosesova was an employee of Canopy Growth Corporation, during which time she received stock options. Mr. Land was an employee of Canopy Growth Corporation, during which time he received stock options, and was a prior employee of GW Pharmaceuticals. Ms. Turcotte is an employee of Canopy Growth Corporation, during which time she has received stock options. Dr. Ware is an employee of Canopy Growth Corporation, during which time he has received stock options. Dr. Bonn-Miller is an employee of Canopy Growth Corporation, during which time he has received stock options. He served on the Board of Directors for AusCann Group Holdings Limited, was a prior employee of Zynerba Pharmaceuticals, and has received consulting fees from Tilray Inc. None of the other authors reports a conflict of interest.

Open Access This article is licensed under a Creative Commons Attribution 4.0 International License, which permits use, sharing, adaptation, distribution and reproduction in any medium or format, as long as you give appropriate credit to the original author(s) and the source, provide a link to the Creative Commons licence, and indicate if changes were made. The images or other third party material in this article are included in the article's Creative Commons licence, unless indicated 
otherwise in a credit line to the material. If material is not included in the article's Creative Commons licence and your intended use is not permitted by statutory regulation or exceeds the permitted use, you will need to obtain permission directly from the copyright holder. To view a copy of this licence, visit http://creativecommons.org/licenses/by/4.0/.

\section{References}

1. Hill KP (2019) Medical use of cannabis in 2019. JAMA. https:// doi.org/10.1001/jama.2019.11868

2. Izzo AA, Borrelli F, Capasso R et al (2009) Non-psychotropic plant cannabinoids: new therapeutic opportunities from an ancient herb. Trends Pharmacol Sci 30:515-527. https://doi.org/10.1016/j. tips.2009.07.006

3. Turner CE, Elsohly MA, Boeren EG (1980) Constituents of Cannabis sativa L. XVII. A review of the natural constituents. J Nat Prod 43:169-234. https://doi.org/10.1021/np50008a001

4. Mehmedic Z, Chandra S, Slade D et al (2010) Potency trends of Delta9-THC and other cannabinoids in confiscated cannabis preparations from 1993 to 2008. J Forensic Sci 55:1209-1217. https://doi.org/10.1111/j.1556-4029.2010.01441.x

5. Potter DJ, Clark P, Brown MB (2008) Potency of delta 9-THC and other cannabinoids in cannabis in England in 2005: implications for psychoactivity and pharmacology. J Forensic Sci 53:90-94. https://doi.org/10.1111/j.1556-4029.2007.00603.x

6. Swift W, Wong A, Li KM et al (2013) Analysis of cannabis seizures in NSW, Australia: cannabis potency and cannabinoid profile. PLoS One 8(7):e70052. https://doi.org/10.1371/journal.pone.0070052

7. Rosenthaler S, Pohn B, Kolmanz C et al (2014) Differences in receptor binding affinity of several phytocannabinoids do not explain their effects on neural cell cultures. Neurotoxicol Teratol 46:49-56. https://doi.org/10.1016/j.ntt.2014.09.003

8. Udoh M, Santiago M, Devenish S et al (2019) Cannabichromene is a cannabinoid CB2 receptor agonist. Br J Pharmacol 176:45374547. https://doi.org/10.1111/bph.14815

9. Ligresti A, Moriello AS, Starowicz K et al (2006) Antitumor activity of plant cannabinoids with emphasis on the effect of cannabidiol on human breast carcinoma. J Pharmacol Exp Ther 318:1375-1387. https://doi.org/10.1124/jpet.106.105247

10. De Petrocellis L, Ligresti A, Moriello AS et al (2011) Effects of cannabinoids and cannabinoid-enriched cannabis extracts on TRP channels and endocannabinoid metabolic enzymes. British J Pharmacol 163:1479-1494. https://doi.org/10.1111/j.1476-5381. 2010.001166.x

11. De Petrocellis L, Vellani V, Schiano-Moriello A et al (2008) Plantderived cannabinoids modulate the activity of transient receptor potential channels of ankyrin type-1 and melastatin type-8. J Pharmacol Exp Ther 325:1007-1015. https://doi.org/10.1124/jpet.107.134809

12. Shinjyo N, Di Marzo V (2013) The effect of cannabichromene on adult neural stem/progenitor cells. Neurochem Int 63:432-437. https://doi.org/10.1016/j.neuint.2013.08.002

13. Turner CE, Elsohly MA (1981) Biological activity of cannabichromene, its homologs and isomers. J Clin Pharmacol 21:283SS291. https://doi.org/10.1002/j.1552-4604.1981.tb02606.x

14. Davis WM, Hatoum NS (1983) Neurobehavioral actions of cannabichromene and interactions with $\Delta 9$-tetrahydrocannabinol. Gen Pharmacol 14:247-252. https://doi.org/10.1016/03063623(83)90004-6

15. Appendino G, Gibbons S, Giana A et al (2008) Antibacterial cannabinoids from Cannabis sativa: a structure-activity study. J Nat Prod 71:1427-1430. https://doi.org/10.1021/np8002673

16. DeLong GT, Wolf CE, Poklis A et al (2010) Pharmacological evaluation of the natural constituent of Cannabis sativa, cannabichromene and its modulation by delta(9)tetrahydrocannabinol. Drug Alcohol Depend 112:126-133. https://doi.org/10.1016/j.drugalcdep.2010.05.019

17. El-Alfy AT, Ivey K, Robinson K et al (2010) Antidepressantlike effect of delta9-tetrahydrocannabinol and other cannabinoids isolated from Cannabis sativa L. Pharmacol Biochem Behav 95:434-442. https://doi.org/10.1016/j.pbb.2010.03.004

18. Tubaro A, Giangaspero A, Sosa S et al (2010) Comparative topical anti-inflammatory activity of cannabinoids and cannabivarins. Fitoterapia 81:816-819. https://doi.org/10.1016/j.fitote. 2010.04.009

19. Maione S, Piscitelli F, Gatta L et al (2011) Non-psychoactive cannabinoids modulate the descending pathway of antinociception in anaesthetized rats through several mechanisms of action. British J Pharmacol 162:584-596. https://doi.org/10.1111/j. 1476-5381.2010.01063.x

20. Izzo AA, Capasso R, Aviello G et al (2012) Inhibitory effect of cannabichromene, a major non-psychotropic cannabinoid extracted from Cannabis sativa, on inflammation-induced hypermotility in mice. Br J Pharmacol 166:1444-1460. https:// doi.org/10.1111/j.1476-5381.2012.01879.x

21. Romano B, Borrelli F, Fasolino I et al (2013) The cannabinoid TRPA1 agonist cannabichromene inhibits nitric oxide production in macrophages and ameliorates murine colitis. Br J Pharmacol 169:213-229. https://doi.org/10.1111/bph.12120

22. Klawitter J, Sempio C, Morlein S et al (2017) An atmospheric pressure chemical ionization MS/MS assay using online extraction for the analysis of 11 cannabinoids and metabolites in human plasma and urine. Ther Drug Monit 39:556-564. https:// doi.org/10.1097/FTD.0000000000000427

23. Huntsman RJ, Tang-Wai R, Alcorn J et al (2019) Dosage related efficacy and tolerability of cannabidiol in children with treatment-resistant epileptic encephalopathy: preliminary results of the CARE-E study. Front Neurol 10:716. https://doi.org/10. 3389/fneur.2019.00716

24. Peters EN, Mosesova I, MacNair L et al (2021) Safety, pharmacokinetics, and pharmacodynamics of Spectrum Yellow oil in healthy participants. J Anal Toxicol bkab026. https://doi.org/ 10.1093/jat/bkab026. Online ahead of print

25. Guy GW, Robson PJ (2004) A phase I, double blind, three-way crossover study to assess the pharmacokinetic profile of cannabis based medicine extract (CBME) administered sublingually in variant cannabinoid ratios in normal healthy male volunteers (GWPK0215). Journal of Cannabis Therapeutics 3:121-152. https://doi.org/10.1300/J175v03n04_02

26. Arkell TR, Lintzeris N, Kevin RC et al (2019) Cannabidiol (CBD) content in vaporized cannabis does not prevent tetrahydrocannabinol (THC)-induced impairment of driving and cognition. Psychopharmacology 236:2713-2724. https://doi.org/10. 1007/s00213-019-05246-8

27. Nadulski T, Pragst F, Weinberg G et al (2005) Randomized, doubleblind, placebo-controlled study about the effects of cannabidiol (CBD) on the pharmacokinetics of Delta9-tetrahydrocannabinol (THC) after oral application of THC verses standardized cannabis extract. Ther Drug Monit 27:799-810. https://doi.org/10.1097/01.ftd.0000177223. 19294.5c

28. Freeman AM, Petrilli K, Lees R et al (2019) How does cannabidiol (CBD) influence the acute effects of delta-9-tetrahydrocannabinol (THC) in humans? A systematic review. Neurosci Biobehav Rev 107:696-712. https://doi.org/10.1016/j.neubiorev.2019.09.036

Publisher's Note Springer Nature remains neutral with regard to jurisdictional claims in published maps and institutional affiliations. 